\title{
Controlled nanostructuration of polycrystalline tungsten thin films
}

\author{
B. Girault, ${ }^{1,2, a)}$ D. Eyidi, ${ }^{1}$ P. Goudeau, ${ }^{1}$ T. Sauvage,${ }^{3}$ P. Guerin, ${ }^{1}$ E. Le Bourhis, ${ }^{1}$ \\ and P.-O. Renault ${ }^{1}$ \\ ${ }^{1}$ Institut P' (UPR 3346 CNRS), Université de Poitiers, ENSMA, Bd Pierre et Marie Curie, \\ 86962 Futuroscope Cedex, France \\ ${ }^{2}$ Institut de Recherche en Génie Civil et Mécanique (UMR CNRS 6183), LUNAM Université, \\ Université de Nantes, Centrale Nantes, CRTT, 37 Bd de l'Université, BP 406, \\ 44602 Saint-Nazaire Cedex, France \\ ${ }^{3}$ CEMHTI/CNRS (UPR 3079 CNRS), Université d'Orléans, 3 A rue de la Férollerie, \\ 45071 Orléans Cedex 2, France
}

(Received 2 February 2013; accepted 16 April 2013; published online 7 May 2013)

\begin{abstract}
Nanostructured tungsten thin films have been obtained by ion beam sputtering technique stopping periodically the growing. The total thickness was maintained constant while nanostructure control was obtained using different stopping periods in order to induce film stratification. The effect of tungsten sublayers' thicknesses on film composition, residual stresses, and crystalline texture evolution has been established. Our study reveals that tungsten crystallizes in both stable $\alpha$ - and metastable $\beta$-phases and that volume proportions evolve with deposited sublayers' thicknesses. $\alpha$-W phase shows original fiber texture development with two major preferential crystallographic orientations, namely, $\alpha-\mathrm{W}\langle 110\rangle$ and unexpectedly $\alpha-\mathrm{W}\langle 111\rangle$ texture components. The partial pressure of oxygen and presence of carbon have been identified as critical parameters for the growth of metastable $\beta$-W phase. Moreover, the texture development of $\alpha-\mathrm{W}$ phase with two texture components is shown to be the result of a competition between crystallographic planes energy minimization and crystallographic orientation channeling effect maximization. Controlled grain size can be achieved for the $\alpha-\mathrm{W}$ phase structure over $3 \mathrm{~nm}$ stratification step. Below, the $\beta$-W phase structure becomes predominant. (C) 2013 AIP Publishing LLC. [http://dx.doi.org/10.1063/1.4803699]
\end{abstract}

\section{INTRODUCTION}

Tungsten body-centered cubic (bcc) material $(\alpha-\mathrm{W})$ assumes several noticeable characteristics ${ }^{1}$ like metal highest melting point $\left(3387^{\circ} \mathrm{C}\right.$ to $\left.3422^{\circ} \mathrm{C}\right)$ and lowest thermal expansion coefficient $\left(\alpha=4.5 \times 10^{-6} \mathrm{~K}^{-1}\right)$. From a mechanical point of view, it presents considerable hardness and toughness and excellent mechanical properties at high temperatures. Tungsten features high compression and elastic moduli, high thermal creep resistance, high thermal and electrical conductivity, and a high coefficient of electron emission. Nanostructure-controlled tungsten-based materials are then potentially promising for many applications. ${ }^{2,3}$

Tungsten crystallizes in two different phases: the equilibrium pure phase, so-called $\alpha-\mathrm{W}$ which is body-centered cubic (space group Im-3m), and a metastable one called $\beta$-W with A15 structure (space group Pm-3n). It is reported that $\beta$-W is stabilized by a low oxygen concentration within tungsten lattice ${ }^{4-6}$ inducing a tensile stress state. ${ }^{7}$ Moreover, the mechanical behavior of $\beta-\mathrm{W}$ drastically differs from $\alpha-\mathrm{W}$. Indeed, systems presenting those two phases, like $\mathrm{FeCr}^{8}$ often show higher hardness for the $\beta$-phase, whereas the elastic modulus remains unchanged. Only few studies report on tungsten metastable phase, ${ }^{4,9-12}$ particularly its development in nanostructured materials, ${ }^{13-16}$ in which stabilization is attributed to impurities. . $^{67-27}$

\footnotetext{
${ }^{\text {a) }}$ Author to whom correspondence should be addressed. Electronic mail: baptiste.girault@univ-nantes.fr. Tel.: +33 240172 628. Fax: +33 240172 618.
}

As regards to physical vapor deposition (PVD), for nanometer length scale (period of the depositing sequence), mechanical properties differ significantly from their bulk counterparts. $^{28-34}$ The processes responsible for these changes are not fully understood yet and are believed to be caused by an increase in grain-surface and grain-boundary volumes, which become dominant over the bulk at the nanoscale. In a film, changes are further caused by the boundary conditions at the free surface and interface with the substrate which become non negligible for small thicknesses. ${ }^{35,36}$

It is then of utmost importance to control and tailor the nanostructure of $\mathrm{W}$ coatings. This requires a full understanding of the growing of both $\alpha$ - and $\beta$-phases. Grain size and texture are to be characterized at different scales while residual stresses are to be analyzed in view of the structure and deposition conditions. X-Ray Diffraction (XRD) is one of the most commonly used techniques to determine thin films structural characteristics (texture, grain size, etc.) in relation with intrinsic mechanical properties such as residual stress state in small volumes. ${ }^{37,38}$ It is phase-selective and allows determination of both the mechanical and microstructural states of the diffracting phases. However, the extracted information is averaged over the irradiated volume of the film. Complementary measurements are then necessary to obtain local structural information in the thin film. In particular, Transmission Electron Microscopy (TEM) observations on cross-sectional specimens are then relevant to provide structural information at a sub-nanometer scale.

The present paper reports on tungsten microstructure evolution of nanostructured thin films which have been 
elaborated by Ion Beam Sputtering (IBS) using a step by step procedure. In order to control grain size in the nanometer range, a sequenced deposition procedure has been employed to stop grain growth during film thickening. This experimental work attempts to explain both the origin and the evolution of $\beta-\mathrm{W}$ in nanocrystalline materials as the tungsten sublayers' thickness changes and the existence of an uncommon texture in nanostructured $\alpha-\mathrm{W}$. The nanostructures of tungsten films have been explored through XRD and cross-sectional TEM in order to investigate phase, crystallite orientation, and grain size. Those measurements have been correlated to residual stress state determined through both XRD and curvature stress measurements. $\beta$-W phase presence is discussed in detail and we show how the impurities set during the deposition affect the residual stress state and the phase development of tungsten nanomaterials. The predominance of this unstable phase for $\mathrm{W}$ crystallite sizes below $3 \mathrm{~nm}$ could then be explained in view of this relationship between impurities and $\beta$-phase stabilization.

\section{EXPERIMENTAL TECHNIQUES}

\section{A. Samples preparation}

The sequenced tungsten depositions were performed at room temperature through IBS with a focused argon ion-gun sputtering beam at $1.2 \mathrm{keV}$ (multi-cusp radio frequency source) in a NORDIKO-3000 system. During sample depositions, the ion-gun was supplied with a constant current ( $80 \mathrm{~mA})$ and constant Ar flux of 10 standard cubic centimeters per minute (SCCM). The $150 \mathrm{~mm}$ in diameter targets have been sputtered for $10 \mathrm{~min}$ prior to deposition, allowing for both ion-gun stabilization and target surface cleaning. The ion-gun axis was $45^{\circ}$-tilted from the normal of the target surface, latter set opposite to sample surface. An elliptical diaphragm at the ion-gun exit allowed getting a circular sputtered surface of $80 \mathrm{~mm}$ in diameter on the target to ensure a good purity of sputtered atoms. Those characteristics lead to deposited atom energy distribution centered around $5 \mathrm{eV}$ with a non-negligible tail (10\% of contribution) between 5 and $100 \mathrm{eV}$. Thin film deposition was performed in a no load-locked IBS chamber equipped with two cryogenic pumps. Referring to pump characteristics, the initial chamber vacuum (base pressure of $2 \times 10^{-6} \mathrm{~Pa}$ ) contained traces of residual water and hydrogen. Regarding the working pressure $\left(\sim 10^{-2} \mathrm{~Pa}\right)$, the mean free path is determined to be longer than the target-substrate distance $(30 \mathrm{~cm})$, leading to non-thermalized incident atoms with high residual stresses built in the deposited coating.

Two types of substrates were used: 200 and $650 \mu \mathrm{m}$ thick, naturally oxidized, Si (001) wafers. They were preliminary cleaned with acetone and ethanol, and finally dried with an argon gas jet prior to their introduction in the deposition chamber in a single run. Tungsten growing rate was previously calibrated with X-Ray Reflectometry (XRR) and found to be $0.05 \mathrm{~nm} \mathrm{~s}^{-1}$. Thin films were deposited using a $200 \mathrm{~mm}$ diameter shutter localized close to the substrate holder allowing either to protect or to expose the sample surface to the sputtered atoms. The shutter round trip duration was lower than $1 \mathrm{~s}$. The sequenced tungsten depositions were performed considering constant $60 \mathrm{~s}$ breaking time on tungsten target while ion-sputtering process remained unchanged.

Sequenced tungsten deposition sample series was prepared with different tungsten sublayers' thicknesses ranging from 1 up to $16 \mathrm{~nm}$ and labeled $\mathrm{W} / \mathrm{W} \mathrm{x} / \mathrm{x}$, with $\mathrm{x}$ referring to nominal tungsten sublayers' thickness in nanometers. The total thickness was maintained constant around $200 \mathrm{~nm}$ adjusting the number of cycles with regard to sublayers' thicknesses.

\section{B. Characterization methods}

\section{X-ray structure analysis}

Systematic qualitative phase analyses were performed on each sample with an INEL XRG 3000 x-ray diffractometer equipped with a linear detector (CPS 120) using $\mathrm{Cr}-\mathrm{K}_{\alpha}$ radiation $\left(\lambda_{\mathrm{Cr}-\mathrm{K} \alpha}=0.22897 \mathrm{~nm}\right)$ in an asymmetric $\Omega / 2 \theta$ geometry $\left(\Omega=30^{\circ}\right)$.

Additional XRD measurements were carried out on a four-circle SEIFERT XRD 3000 goniometer $\left(\mathrm{Cu}-\mathrm{K}_{\alpha}\right.$ radiation, $\lambda_{\mathrm{Cu}-\mathrm{K} \alpha}=0.15406 \mathrm{~nm}$ ) with either a point focus to investigate films texture and residual stresses, or a line focus to characterize thin film stratification (XRR).

Pole figures were systematically carried out on tungsten $\alpha-\{110\}, \alpha-\{200\}$, and $\alpha-\{211\}$ diffraction peaks in order to determine tungsten main texture component. Pole figures were performed with $\psi$-angles (angle between the normal to the sample surface and the normal to the diffracting planes) ranging from $1.3^{\circ}$ to $78.8^{\circ}$ with a $2.5^{\circ}$ step and $\varphi$-angles (rotational angle around the normal to the sample surface) comprise between $0^{\circ}$ and $360^{\circ}$ with a $5^{\circ}$ step. The integration time was $6 \mathrm{~s}$ per point.

\section{Stress determination}

Two methods have been used in order to investigate sample mechanical stress state: $x$-ray diffraction and curvature measurements. X-ray stress analysis yields the crystalline in-grain stress of the analyzed phases (i.e., $\alpha-\mathrm{W}$ in our present work) while curvature measurements yields the average stress in the whole thin film volume (i.e., $\alpha-\mathrm{W}, \beta-\mathrm{W}$, and disordered regions such as grain boundaries (GB)).

Regarding x-ray analysis, the " $\sin ^{2} \psi$ method" was used to evaluate intra-granular macroscopic residual stresses in $\alpha$ $\mathrm{W}$ phase. This method, based on the shift of the diffraction peak position, is particularly suitable in the case of a mechanically locally isotropic material like $\alpha-\mathrm{W}$. Moreover, considering the deposition geometry, we assume a planar equi-biaxial stress state and thus the " $\varepsilon$ - $\sin ^{2} \psi$ relation" can be written as

$$
\varepsilon_{\varphi \psi}^{X R D}=\frac{1+v}{E} \sigma^{X R D} \sin ^{2} \psi-\frac{2 v}{E} \sigma^{X R D},
$$

where $\varepsilon_{\varphi \psi}^{X R D}$ is the strain in the direction defined by $\varphi$ and $\psi$ (being, respectively, azimuth and inclination angles of measurement), $\sigma^{X R D}$ is the equi-biaxial residual stress, and $E$ and $\nu$ are the Young's modulus and the Poisson's ratio of the studied material, respectively. Here, the strain rational definition $\varepsilon_{\varphi \psi}^{X R D}=\ln \left(a_{h k l}^{X R D} / a_{0}^{X R D}\right)$ is used, $a_{0}^{X R D}$ being the 
stress-free lattice parameter and $a_{h k l}^{X R D}$ being the measured lattice parameter. Latter values were deduced from $\alpha-\mathrm{W}\{110\}$, $\alpha-\mathrm{W}\{200\}$, and $\alpha-\mathrm{W}\{211\}$ diffraction peaks acquired around pole directions, and are thus related to crystallites that contribute to texture components. As a first approximation, $\alpha-\mathrm{W}$ bulk elastic constants $(E=411 \mathrm{GPa}$ and $\nu=0.28)$ were used. Due to poor available data on mechanical properties of tungsten $\beta$-phase in the literature (particularly considering nanostructured materials) and the low diffraction-peak intensity, no residual stress analysis has been performed in this work on $\beta$-W.

Thin film macroscopic residual stresses were determined using the curvature method. Ante- and post-deposition curvatures were measured using a Dektak ${ }^{\circledR}$ IIa profilometer and $200 \mu \mathrm{m}$-thick Si cantilever substrates. Since the substrate is much thicker than the deposited thin film and considering continuous strain at film-substrate interface, Stoney's relationship applies

$$
\sigma_{f}^{C M}=\frac{E_{s}}{1-v_{s}} \times \frac{t_{s}^{2}}{6 t_{f}}\left[\frac{1}{R_{\text {final }}}-\frac{1}{R_{\text {initial }}}\right],
$$

with $\frac{E_{s}}{1-v_{s}}=180.5 \mathrm{GPa}$ for Si (001) wafers. $\sigma_{f}^{C M}$ is the macroscopic stress set in the film; $E_{s}$ and $v_{s}$ the substrate Young's modulus and Poisson's ratio, respectively; $t_{s}$ and $t_{f}$ the substrate and film thicknesses; and finally, $R_{\text {initial }}$ and $R_{\text {final }}$ the curvature radii before and after deposition. Let us notice that curvature method does not require the knowledge of thin film elastic constants contrarily to x-ray stress measurement where bulk W elastic constants are considered.

\section{Transmission electron microscopy observations}

TEM experiments were carried out on W/W 1/1 and W/ W 16/16 coatings. Specimens were prepared as follows: two pieces of $2.7 \times 1.5 \times 0.65 \mathrm{~mm}^{3}$ in size were cut from a $650 \mu \mathrm{m}$-thick Si-coated substrate with a wire saw and bonded in pairs, the film surfaces stuck to each other by M-Bond ${ }^{\mathrm{TM}}$ glue. The TEM specimens were successively mirror polished with silicon carbide disk, dimpled (DG, Gatan model 656), and ion-milled to electron transparency with a Precision Ion Polishing System (PIPS, Gatan model 691). TEM observations were performed on a JEOL 2200-FS equipped with a field-emission gun, an in-column Omega energy filter and a Scanning TEM (STEM) unit. High-Resolution TEM (HRTEM) images were also acquired to investigate the thin film nanostructuration.

Electron diffraction patterns were acquired to analyze the thin film phase local orientations. Red Blue Green (RBG) images were generated from Inverse Fast Fourier Transforms (IFFT) related to HRTEM micrographs. Superposition of dark-field images allowed qualitative stereometry of phase and crystallographic orientations in the observation plane.

For a further understanding of the $\beta$-W phase development, and since tungsten $\beta$-phase could either be a low oxidized or carbon stabilized phase, elemental composition measurements were carried out on W/W 1/1 and W/W 8/8 samples by Nuclear Reaction Analysis (NRA) technique to obtain precise in-depth elemental composition in the film: oxygen and carbon atomic concentrations were determined using ${ }^{16} \mathrm{O}(\mathrm{d}, \alpha){ }^{14} \mathrm{~N}$ and ${ }^{12} \mathrm{C}(\mathrm{d}, \mathrm{p}){ }^{13} \mathrm{C}$ reactions, respectively. Spectra have been simulated using SIMNRA program.

\section{RESULTS}

\section{A. Phase analysis}

Fig. 1 shows $\Omega / 2 \theta$ diffractograms obtained on W/W $1 / 1$, W/W 2/2, W/W 3/3, W/W 8/8, and W/W 16/16 samples. On the one hand, $\alpha-\mathrm{W}\{200\}$ and $\alpha-\mathrm{W}\{211\}$ diffraction peaks are systematically present on sequenced tungsten deposition phase diagrams except for W/W $1 / 1$, where $\alpha-\mathrm{W}\{200\}$ and $\alpha-\mathrm{W}\{211\}$ peaks vanish to the benefit of $\beta-\mathrm{W}\{321\}$ one indicating that the sample is mostly composed of the A15 tungsten structure. The analysis of $\alpha$ and $\beta$ tungsten peak relative intensities suggests that for a sequenced tungsten deposition with sublayers' thickness above $3 \mathrm{~nm}, \alpha-\mathrm{W}$ (bcc) phase is mainly crystallized and develops a preferential crystallographic orientation.

On the other hand, $\beta$-W $\{200\}$ and $\beta$-W $\{211\}$ diffraction peaks, located at $2 \theta=53.9^{\circ}$ and $67.5^{\circ}$, respectively, and typical of tungsten A15 structure indicate systematic tungsten $\beta$-phase development for all sequenced tungsten depositions ( $\leq 10 \%$ volume fraction for tungsten sublayers' thicknesses greater than or equal to $3 \mathrm{~nm}$ ).

The respective Full Width at Half Maximum (FWHM) of the $\alpha-\mathrm{W}\{110\}, \alpha-\mathrm{W}\{200\}$, and $\alpha-\mathrm{W}\{211\}$ Bragg's peaks remained unchanged down to a period of $3 \mathrm{~nm}$ (included). Similar values of the stress-free lattice parameter $a_{0}^{X R D}$ (see Table I) were obtained so that only a small evolution of the grain size may be expected. A progressive diffraction peak widening is observed from W/W $3 / 3$ down to W/W $1 / 1$ coupled with a peak position shift towards $\beta-\mathrm{W}$ phase Bragg's peaks.

Considering the large increase of the $\alpha$-W stress-free lattice parameters from $\mathrm{W} / \mathrm{W} 3 / 3$ to $\mathrm{W} / \mathrm{W} 2 / 2$, the observed widening of the different diffraction peaks should rather be

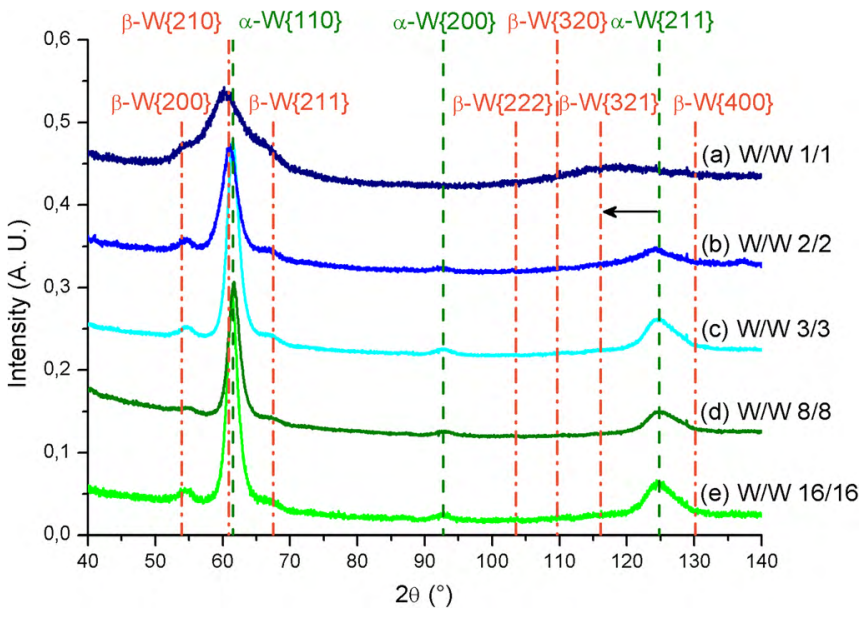

FIG. $1 . \Omega / 2 \theta$ diffractograms obtained on the sequenced tungsten deposition sample series in $30^{\circ}$ of incidence and performed with $\mathrm{Cr}-\mathrm{K}_{\alpha}$ radiation: (a) W/W 1/1, (b) W/W 2/2, (c) W/W 3/3, (d) W/W 8/8, and (e) W/W 16/16. Green and orange dotted vertical lines represent bulk diffraction peak position of the $\alpha$ - and $\beta$-tungsten phases, respectively (International Center for Diffraction Data-Powder Diffraction File (ICDD) No. 4-806 for $\alpha-\mathrm{W}$ and No. 47-1319 for $\beta$-W). 
TABLE I. Morphology, structure, and mechanical state of sequenced tungsten deposition series: $\Lambda, \sigma_{f}^{C M}$, and $\sigma_{\alpha-\mathrm{W}}^{\mathrm{XRD}}$ correspond, respectively, to period (i.e., tungsten sublayers' thickness), film, and $\alpha$-W residual stress. Residual stresses in the film were obtained by substrate curvature while residual stresses in tungsten sublayers were determined through XRD measurements: pole direction discrimination allowed the knowledge of stress-free lattice parameter and residual stress associated to $\langle 110\rangle$ and $\langle 111\rangle$ orientated grains. Associated uncertainties are about $10 \%$.

\begin{tabular}{|c|c|c|c|c|c|c|c|}
\hline \multirow[b]{2}{*}{ Sample designation } & \multicolumn{2}{|c|}{ Thicknesses } & \multicolumn{2}{|c|}{ Structure } & \multicolumn{3}{|c|}{ Residual stresses } \\
\hline & $\Lambda(\mathrm{nm})$ & $\mathrm{t}_{\mathrm{f}}(\mathrm{nm})$ & $\beta$-W phase & Texture $\alpha-\mathrm{W}$ & $a_{0 \alpha-\mathrm{W}}^{X R D}(\mathrm{~nm})$ & $\sigma_{\alpha-\mathrm{W}}^{X R D}(\mathrm{GPa})$ & $\sigma_{f}^{C M}(\mathrm{GPa}$ \\
\hline $\mathrm{W} / \mathrm{W}$ & $\cdots$ & 213 & Major & $\ldots$ & $\ldots$ & $\cdots$ & -1.6 \\
\hline \multicolumn{8}{|l|}{$1 / 1$} \\
\hline $\mathrm{W} / \mathrm{W}$ & 2.0 & 203 & Minor & $\{110\}$ & 0.3196 & -4.5 & -2.6 \\
\hline $2 / 2$ & & & & $\{111\}$ & 0.3218 & -8.9 & \\
\hline $\mathrm{W} / \mathrm{W}$ & 3.1 & 217 & Low & $\{110\}$ & 0.3173 & -3.4 & -2.7 \\
\hline $3 / 3$ & & & & $\{111\}$ & 0.3189 & -5.7 & \\
\hline $\mathrm{W} / \mathrm{W}$ & 7.9 & 197 & Low & $\{110\}$ & 0.3178 & -3.5 & -2.9 \\
\hline $8 / 8$ & & & & $\{111\}$ & 0.3184 & -6.0 & \\
\hline $\mathrm{W} / \mathrm{W}$ & 14.6 & 195 & Low & $\{110\}$ & 0.3181 & -3.8 & -2.7 \\
\hline $16 / 16$ & & & & $\{111\}$ & 0.3187 & -6.0 & \\
\hline
\end{tabular}

attributed to micro-deformation (interstitial or substitution atoms). So crystallites size collapses and/or $\beta$-W phase volume fraction increases (solely regarding $\alpha-\mathrm{W}\{110\}$ ), growth of $\beta-\mathrm{W}\{200\}, \beta-\mathrm{W}\{210\}$ and $\beta$-W $\{211\}$ could also potentially contribute to FWHM enlargement.

Phase analysis revealed that sequenced tungsten deposition (sublayers over $3 \mathrm{~nm}$ ) mainly induces $\alpha-\mathrm{W}$ (bcc) with residual $\beta$-W phase while $\mathrm{W} / \mathrm{W} 1 / 1$ seems to be exclusively composed by A15 tungsten structure.

\section{B. Sample stratification}

Fig. 2 shows XRR diagrams obtained on the sequenced tungsten deposited on silicon substrates. No significant evolution of the critical reflection angle, $\theta_{c}$, is observed, but its value was found to be systematically slightly smaller $(<8 \%)$ than the bulk one $\left(\theta_{c}^{b}=0.552^{\circ}\right.$ for $\mathrm{Cu}-\mathrm{K}_{\alpha}$ wavelength). This result could be related to roughness of either sample surface or sublayers' interfaces and/or surface oxidation since the critical angle is related to the film density.

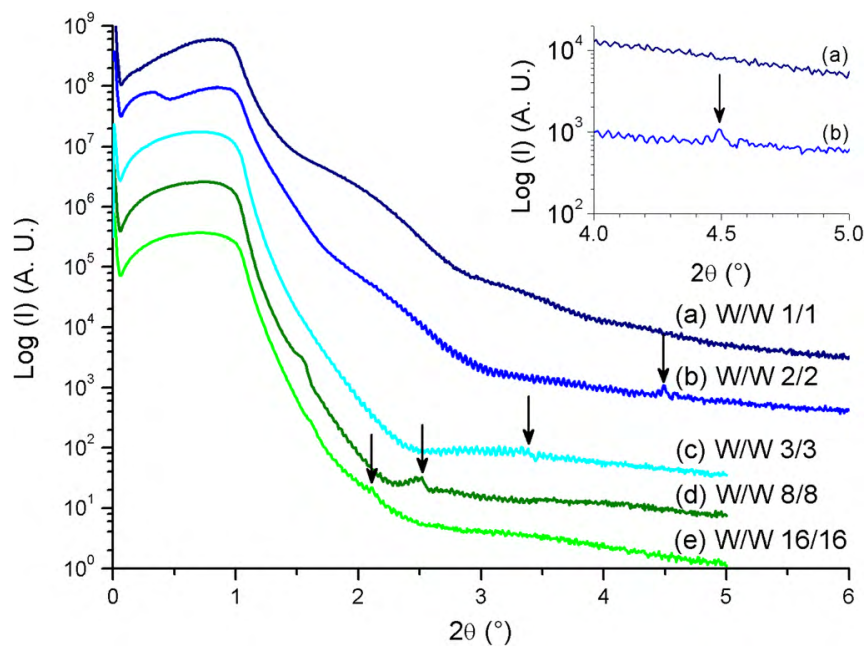

FIG. 2. Reflectometry diagrams obtained on the sequenced tungsten deposition sample series and performed with $\mathrm{Cu}-\mathrm{K}_{\alpha}$ radiation: (a) W/W 1/1, (b) W/ $\mathrm{W} 2 / 2$, (c) W/W 3/3, (d) W/W 8/8, and (e) W/W 16/16. The arrows indicate emphasize small angle Bragg's peak modulation, while inset is showing the diffractogram enlargement around the W/W 2/2 peak.
Providing sufficient counting time, each XRR diagram displays a low angle Bragg's peak (amplitude alleviation of Kiessig's fringes) with the exception of W/W 1/1. Modulations indicate coating stratification and were unexpected since reflectometry signal is based on electronic density differences while only tungsten has been sputtered. Reflectometry signals display similar low intensity and poorly defined shape indicating similar interfaces, independently of the multilayered sample. Nevertheless, a strong correlation is found between sputtering sequence and tungsten sublayers' thicknesses deduced from reflectometry measurements (Table I). The step by step growth procedure clearly induces a stratification that should stop the grain growth during film thickening, and thus, allows a control of the grain size in the nanometer range (from 1 up to $16 \mathrm{~nm}$ ).

\section{Texture analysis}

Fig. 3 shows pole figure of $\mathrm{W} / \mathrm{W} 1 / 1$ acquired on $\beta$ $\mathrm{W}\{210\}$ and pole figures performed on $\alpha-\mathrm{W}\{200\}$ diffraction peak of the remaining sequenced tungsten deposition samples (i.e., W/W 2/2, W/W 3/3, W/W 8/8, and W/W 16/16). $\beta$-W crystallographic orientation investigations have been carried out upon specific $\beta$-W diffraction peak $(\beta-\mathrm{W}\{200\}$ and $\beta$-W $\{210\}) \psi$-scan. W/W $1 / 1$ being quasi-exclusively constituted of $\beta$-W phase (negligible $\alpha-\mathrm{W}$ phase volume proportion) pole figure has been performed on $\beta-\mathrm{W}\{210\}$.

The pole figure of $\mathrm{W} / \mathrm{W} 1 / 1$ showed no preferential crystallographic orientation, i.e., polycrystalline $\beta$-W phase (isotropic texture). Texture investigations ( $\psi$-scan) performed on $\beta$-W $\{200\}$ and $\beta$-W $\{211\}$ for the other coatings also revealed no preferential crystallographic orientation of the $\beta$-phase.

On the contrary, strong preferential crystallographic orientation is observed on $\alpha-\mathrm{W}\{200\}$ pole figures. Radial intensity reinforcements reveal favored grain growth along crystallographic orientations, isotropically distributed in the film plane (fiber texture). The high intensity ring reflects a large volume of $\alpha-\mathrm{W}\{200\}$ diffracting planes at $\psi \sim \pm 55^{\circ}$. This value nearly matches the $54.7^{\circ}$ angle existing between 

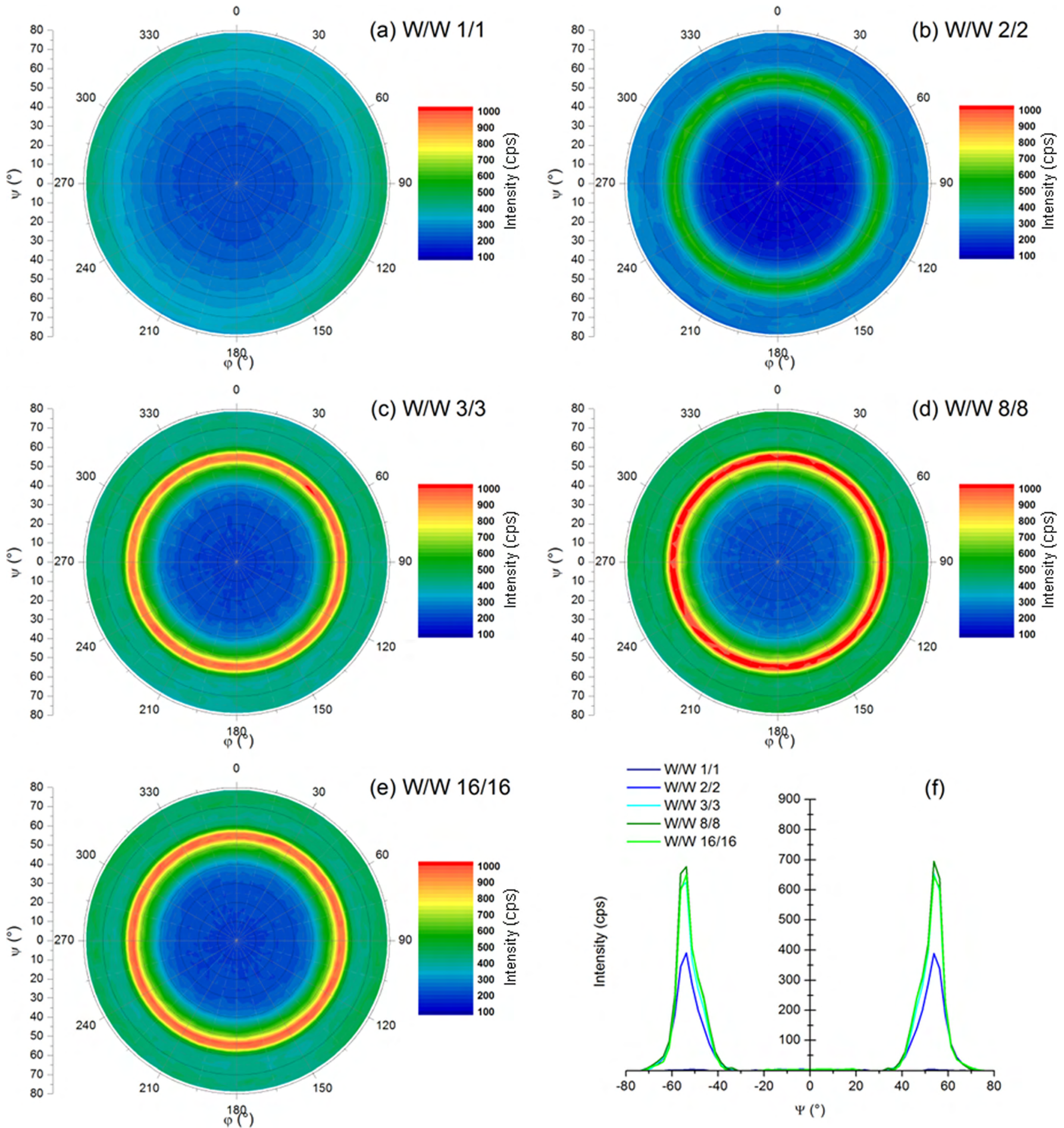

FIG. 3. Pole figure of (a) W/W $1 / 1$ obtained on $\beta$-W $\{210\}$ and the different $\alpha$-W $\{200\}$ pole figures of (b) W/W $2 / 2$, (c) W/W 3/3, (d) W/W 8/8, and (e) W/W 16/16. (f) $\varphi$-averaged $\alpha$-W $\{200\} \psi$-scans where the background has been subtracted.

$\alpha-\mathrm{W}\langle 200\rangle$ and $\alpha-\mathrm{W}\langle 111\rangle$ directions for a cubic structure and indicates thus a high population of $\alpha-\mathrm{W}\langle 111\rangle$ grains oriented along the growth direction. Moreover, precise ring profile (Fig. 3(f)) observation reveals a shouldering, i.e., a contribution of a peak located at $\psi=45^{\circ}$ (angle between $\langle 200\rangle$ and $\langle 110\rangle$ in cubic crystals), indicating a second fiber $\alpha-\mathrm{W}\langle 110\rangle$ texture component. From the relative intensities, lower $\alpha$ $\mathrm{W}\langle 110\rangle$ volume fraction is expected compared to $\alpha-\mathrm{W}\langle 111\rangle$. The angular analyses are consistent with angle observations made on $\alpha-\mathrm{W}\{110\}$ and $\alpha-\mathrm{W}\{211\}$ pole figures. Tungsten sublayers are thus composed of, at least, two sets of grains showing $\alpha-\mathrm{W}\langle 110\rangle$ and $\alpha-\mathrm{W}\langle 111\rangle$ preferential orientations. $\alpha-\mathrm{W}$ crystallographic orientation distributions have been performed on $\alpha-\mathrm{W}\{200\}$ allowing for pure $\alpha$-phase analysis. Indeed, the proximity of $\beta$-W phase diffraction peaks with $\alpha$ $\mathrm{W}\{110\}$ ones and to a less extent $\alpha$-W $\{211\}$ ones (Fig. 1) might induce misinterpretation of the pole figures. Nevertheless, $\alpha-\mathrm{W}\{200\}$ crystallographic investigations were consistent with $\alpha-\mathrm{W}\{110\}$ and $\alpha-\mathrm{W}\{211\}$ pole figure observations despite diffraction peak overlapping. 
Thus, pole figure investigations reveal bimodal preferential crystallographic orientation development in the $\alpha-\mathrm{W}$ phase whereas $\beta$-W shows isotropic texture. Texture development is then not directly influenced by the number of interfaces set in tungsten thin films. On the contrary, texture evolution below $3 \mathrm{~nm}$ thick tungsten sublayers fits volume proportion of $\beta$-W phase changes.

\section{Stress analysis}

Fig. 4 shows logarithmic plots of the measured lattice parameter as a function of $\sin ^{2} \psi$ for W/W 2/2, W/W 3/3, W/ W 8/8, and W/W 16/16. Related compressive stress values are summarized in Table I. Thin film macroscopic residual stress values, $\sigma_{f}^{C M}$ (obtained from curvature method), reveal similar strong compressive stress state built in the sequenced tungsten deposition. W/W 1/1 specimen shows a significantly lower value which can be attributed to the presence of the $\beta$-W phase. Indeed, the residual stresses for this phase are generally found nil or tensile. ${ }^{39}$

XRD measurements allowed selectively determining stresses in the two family grains related to each of the major preferential crystallographic orientations (i.e., $\alpha-\mathrm{W}\langle 110\rangle$ and $\alpha-\mathrm{W}\langle 111\rangle$ oriented grain families, Table I). This was performed discriminating pole directions with respect to texture components. It appears that the grain families with $\alpha$ $\mathrm{W}\langle 110\rangle$ or $\alpha-\mathrm{W}\langle 111\rangle$ oriented along the thin film growth direction present a high compressive stress state with higher stresses in $\alpha-\mathrm{W}\langle 111\rangle$ oriented grains than in $\alpha-\mathrm{W}\langle 110\rangle$ oriented ones. The XRD stress difference between those two texture components is significant and systematically larger than $2 \mathrm{GPa}$ : 4.4 for $\mathrm{W} 2 / 2$ and about 2.4 for $\mathrm{W} \mathrm{3/3,} \mathrm{W8/8,}$ and W16/16. Meanwhile, the curvature's residual stress values are in the same range for the four samples, i.e., about $-2.7 \mathrm{GPa}$.

XRD yields information on the considered $\alpha-\mathrm{W}$ crystalline fraction while the curvature method assesses the whole thin film response with then additional contribution from grain boundaries, interfaces and $\beta$-W.

All stress-free lattice parameters $a_{0}$ are determined to be larger than bulk reference parameter $(0.3165 \mathrm{~nm})$, indicating lattice expansion due to interstitial defects ${ }^{40}$ (Table I). $\alpha-\mathrm{W}\langle 111\rangle$ texture component shows systematically higher $a_{0}$ values than $\alpha-\mathrm{W}\langle 110\rangle$ component, suggesting forced preferential crystallographic orientation ("metastable" texture component), with a difference that increases as the period decreases (when stress for $\alpha-\mathrm{W}\langle 111\rangle$ oriented grains is also the highest).

\section{E. Microstructure observations}

In order to understand the origin of the $\beta$-W phase in our deposition conditions, cross-sectional TEM observations were carried out on both W/W 16/16 (showing a low $\beta$-W volume fraction) and $\mathrm{W} / \mathrm{W} 1 / 1$ (with major $\beta$-W volume fraction) specimens. $\alpha-$ and $\beta-\mathrm{W}$ phases have close inter-reticular
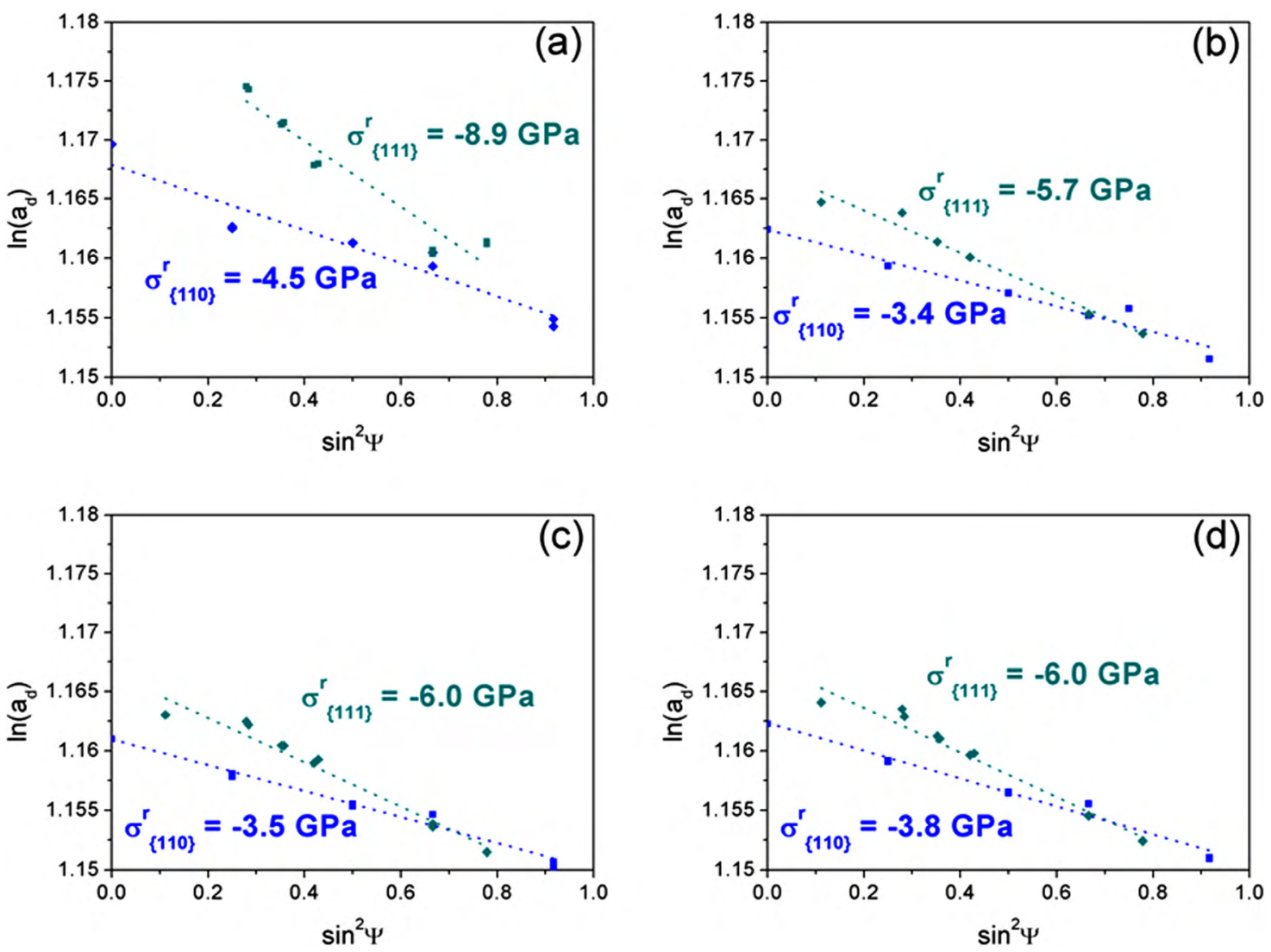

FIG. 4. Logarithmic plots of deformed lattice parameter extracted from XRD measurements carried out on (a) W/W 2/2, (b) W/W 3/3, (c) W/W 8/8, and (d) W/W $16 / 16$ as a function of $\sin ^{2} \psi$. XRD measurements were performed around pole directions discriminating data associated to $\alpha$-W $\langle 110\rangle$ and $\alpha$-W $\langle 111\rangle$ texture components and performed with $\mathrm{Cu}-\mathrm{K}_{\alpha}$ radiation. Blue and green dotted lines represent linear regression considering, respectively, $\alpha$-W $\langle 110\rangle$ and $\alpha$ $\mathrm{W}\langle 111\rangle$ oriented grains. 


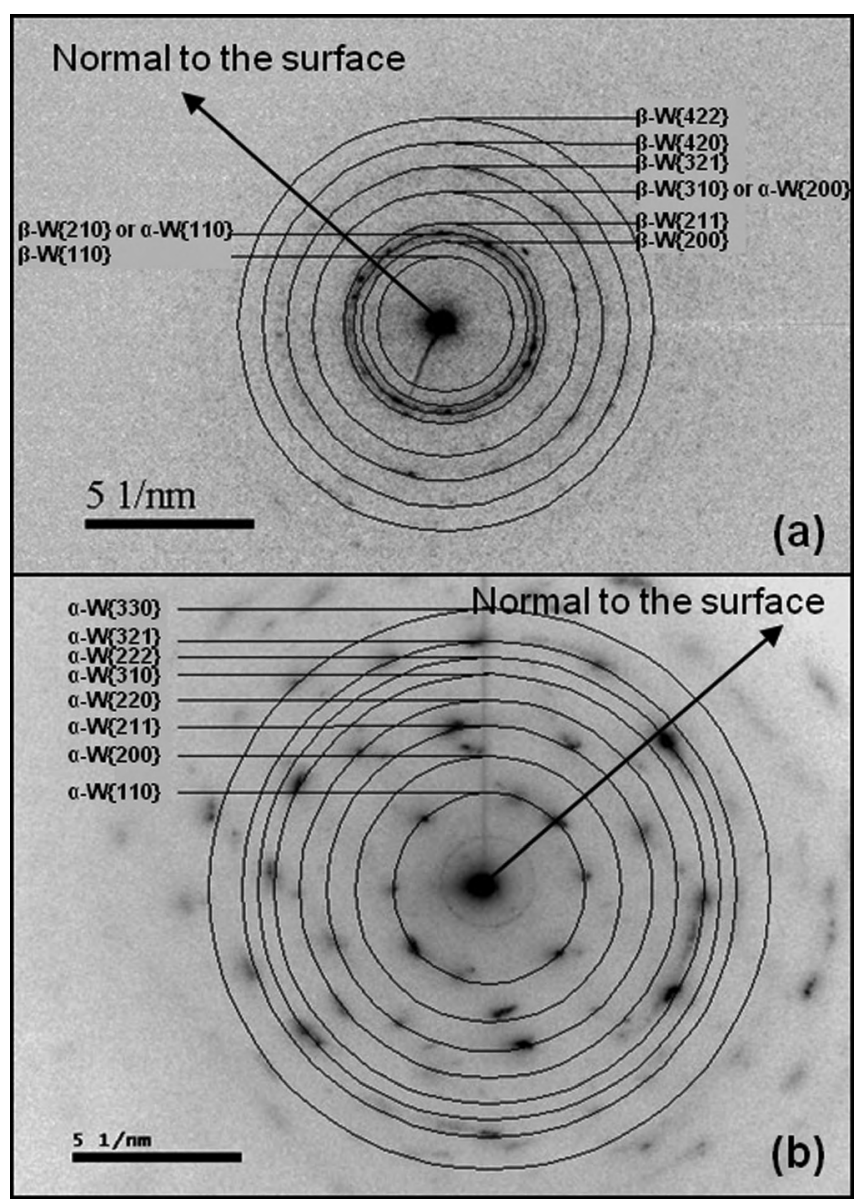

FIG. 5. SAED patterns carried out on (a) W/W 1/1 and (b) W/W 16/16 samples on the whole thin film thickness. Concentric circles represent the different index linked inter-reticular distances.

distances (Fig. 5), only three diffraction spots allow to discriminate unambiguously the phases: $\beta$-W $\{110\}, \beta-\mathrm{W}\{200\}$, and $\beta-\mathrm{W}\{211\}$. The observation of $\beta-\mathrm{W}\{200\} \quad\left(d_{\beta-W\{200\}}\right.$ $=0.2520 \mathrm{~nm})$ and $\beta$-W $\{211\}\left(d_{\beta-W\{211\}}=0.2057 \mathrm{~nm}\right)$ spots on either Selected Area Electron Diffractograms (SAED) or FFT from HRTEM micrographs is a signature of the presence of $\beta-\mathrm{W}$ phase and thus proves the existence of $\beta$-W grains in the observed zone. Nevertheless, the opposite is not systematically true: the absence of these spots is not sufficient to establish that all the remaining spots belong to the $\alpha-\mathrm{W}$ phase. Indeed, the precision on inter-reticular distances reached here by TEM does not exceed a hundredth of nanometer. This implies that $\alpha-\mathrm{W}\{110\}\left(d_{\alpha-W\{110\}}=0.2234 \mathrm{~nm}\right)$ and $\beta$-W $\{210\}\left(d_{\beta-W\{210\}}=0.2254 \mathrm{~nm}\right)$ cannot be distinguished with SAED inter-reticular distance measurements alone. It is also possible to observe diffraction from $\beta$-W $\{210\}$ planes while diffraction conditions for $\beta$-W $\{200\}$ and $\beta$-W $\{211\}$ planes are not fulfilled. Angular correlation analysis between spots is thus needed to index them and implies to record at least two diffracted spots on the SAED or FFT patterns. Finally, relative intensities of diffraction spots and $\beta-\mathrm{W}$ volume fraction might induce such a low signal that $\beta-\mathrm{W}$ phase characteristic spots are not visible on the diffraction pattern. Each observed phenomenon was thus correlated by interreticular distances and FFT on HRTEM images.
SAED patterns shown in Fig. 5 were acquired over the full film thickness. Inter-reticular distances and spot angular correlation analyses carried out on W/W $1 / 1$ specimen reveal that the thin film mainly consists of $\beta$-W. No preferential crystallographic orientation is observed since no intensity reinforcement is found along the normal to the film-substrate interface.

No spots related to the $\beta$-W phase is noticed on $\mathrm{W} / \mathrm{W}$ $16 / 16$ SAED patterns whereas $\alpha-\mathrm{W}\langle 110\rangle$ and $\alpha-\mathrm{W}\langle 222\rangle$ diffraction spots are observed along the growth direction exhibiting the two major $\alpha-\mathrm{W}$ preferential crystallographic orientations, i.e., $\langle 110\rangle$ and $\langle 111\rangle$ directions in agreement with XRD analysis. It should be noticed that the absence of characteristic $\beta$-W structure spots does not allow claiming $\beta$-W phase absence.

Fig. 6(a) shows unprocessed HRTEM images mosaic of W/W 16/16 specimen while FFT associated to each HRTEM image is shown in Fig. 6(b). RBG images obtained from inverse filtering of FFT spots show $\beta$-W grain location (Fig. 6(c)). HRTEM images evidence complex interfaces between the W/W 16/16 thin film and the substrate; dark zones reveal local strains in the TEM specimens. Interface intensity-profile analysis indicated that the silicon substrate progressively loses its crystallographic cubic structure within a $5 \mathrm{~nm}$ thick band when approaching the film-substrate interface. This zone corresponds to $\mathrm{SiO}_{\mathrm{x}}$ amorphous layers. ${ }^{41}$ Moreover, HRTEM shows the existence of one single layer at the film-substrate interface with a thickness of $0.7 \mathrm{~nm}$ that does not match any of the sputtering parameter. It is assumed that this layer appears during the tungsten target cleaning prior to main sputtering sequence. Its growing rate is estimated to be $0.0027 \mathrm{~nm} \mathrm{~s}^{-1}$ (considering layer thickness related to the 10 min target cleaning and measured through TEM). Then considering a $60 \mathrm{~s}$ breaking time between each tungsten sublayer, we expect inter-tungsten sublayers with thickness about $0.14 \mathrm{~nm}$ that is below microscope point resolution $(0.23 \mathrm{~nm})$ and slightly above interplanar distance $(0.1 \mathrm{~nm})$.

FFT in Fig. 6(b) does not show preferential crystallographic orientation and inter-reticular distances of $\beta$-W $\{200\}$, $\beta-\mathrm{W}\{210\}$, or $\alpha-\mathrm{W}\{110\}$ and $\beta-\mathrm{W}\{211\}$. Fig. 6(c) shows RBG images mosaic reconstructed from those FFT considering typical $\beta$-W associated spots, i.e., $\beta$-W\{200\} and $\beta$ $\mathrm{W}\{211\}$. $\beta$-W grains (red, blue, green, and yellow zones) are determined to be mainly located at film-substrate interface. Above this zone the film is mainly composed of $\alpha-\mathrm{W}$ phase. W/W 16/16 grain size is estimated in the range of $10-30 \mathrm{~nm}$ and thus suggests nevertheless partial interface coherency between tungsten sublayers.

HRTEM image of Fig. 7 shows nanostructured W/W $1 / 1$ thin film. FFT performed on two areas separated by few nanometers shows different crystallographic orientations and thus two different nanometer-sized grains, a feature that can be seen all over the thin film. HRTEM images thus confirm thin films nanostructuration in agreement with previously observed FWHM evolution by XRD with tungsten sublayers' thicknesses.

Fig. 8 shows Bright Field TEM (BFTEM) image of W/W 1/1 film-substrate interface and related intensity profile. Analysis revealed again one $2.1 \mathrm{~nm}$ thick amorphous zone (see the FFT) at the interface followed by an intensity 

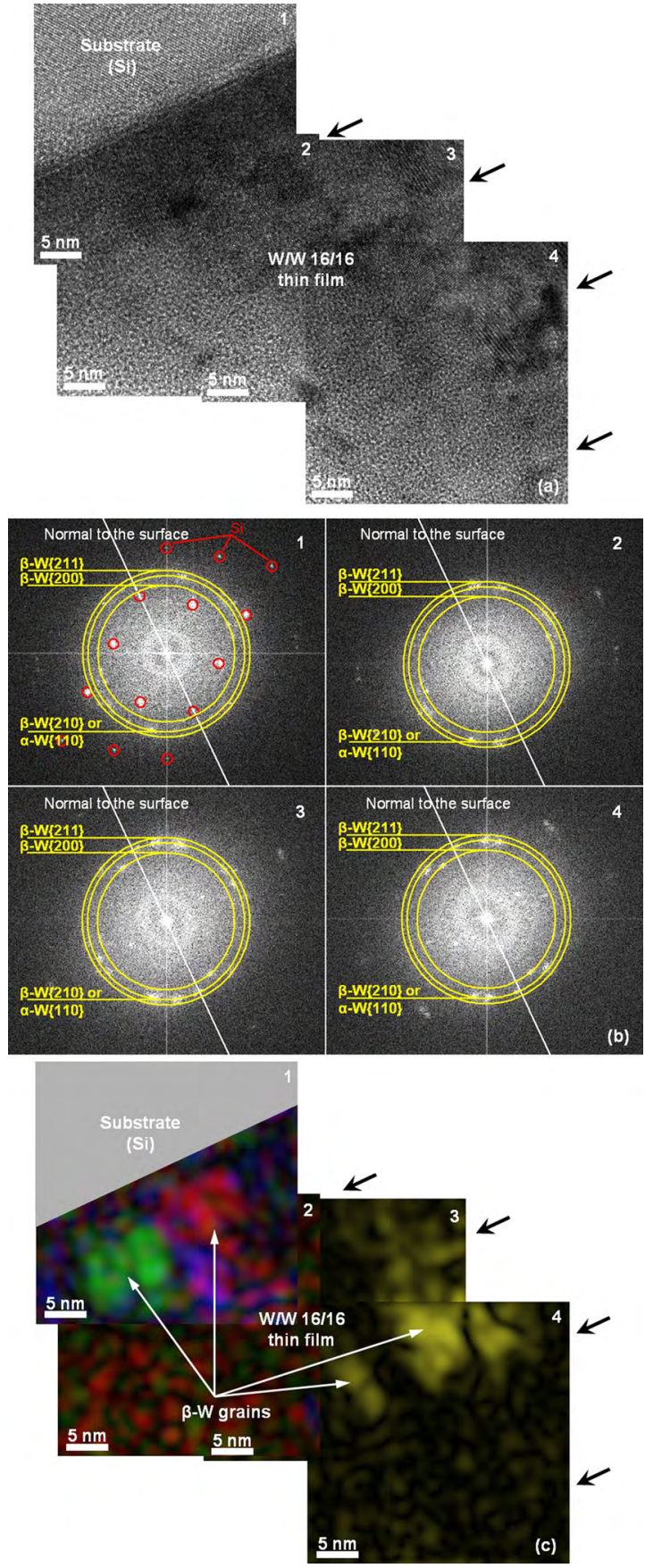

FIG. 6. (a) HRTEM images mosaic of W/W 16/16 specimen (arrows indicate W sublayers' interface positions). (b) FFT associated to each HRTEM image and (c) reconstructed RBG images from IFFT showing $\beta$-W grain location (red, blue, green, and yellow zones). Concentric circles on FFT represent the different index linked inter-reticular distances, punctually observed along different azimuths.

plateau of $1.2 \mathrm{~nm}$ width. However, contrary to W/W 16/16 film-substrate interface, no pre-deposition layer (likely related to tungsten target cleaning) is observed.

\section{F. Carbon and oxygen presence}

Qualitative electron energy-loss spectroscopy (EELS) measurements performed on sample W/W $1 / 1$ along the film-substrate interface and on both sides of it showed an increase of the oxygen-K edge at the film-substrate interface. Additional elemental analyses were carried out on the same

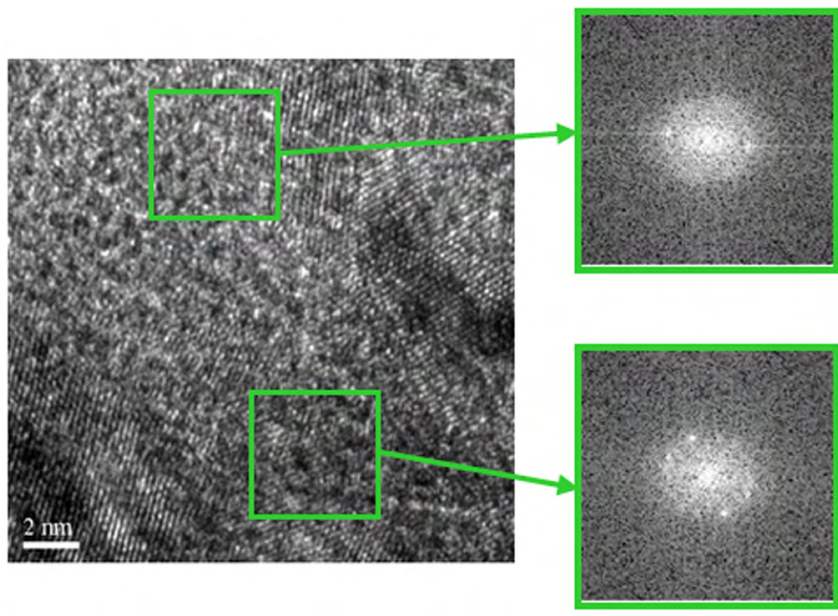

FIG. 7. (a) BF-TEM image of W/W 1/1 specimen and associated local FFT showing different spot patterns, indicating different local crystallographic orientations: (b) and (c).

sample through NRA measurements. NRA spectrum shown in Fig. 9(a) exhibits oxygen peak at film-substrate interface, which is coherent with native oxide layers formed on silicon wafers surface prior to sputtering sequence $\left(\mathrm{SiO}_{\mathrm{x}}\right.$ amorphous layer) as reported in Sec. IIIE, and at film surface. It also shows a low oxygen atomic proportion in volume $(1.5 \pm 0.2$ at. \%). Quantitative analysis on $\mathrm{W} / \mathrm{W} 1 / 1$ reveals also a strong carbon content in volume (16 \pm 1 at. \%).
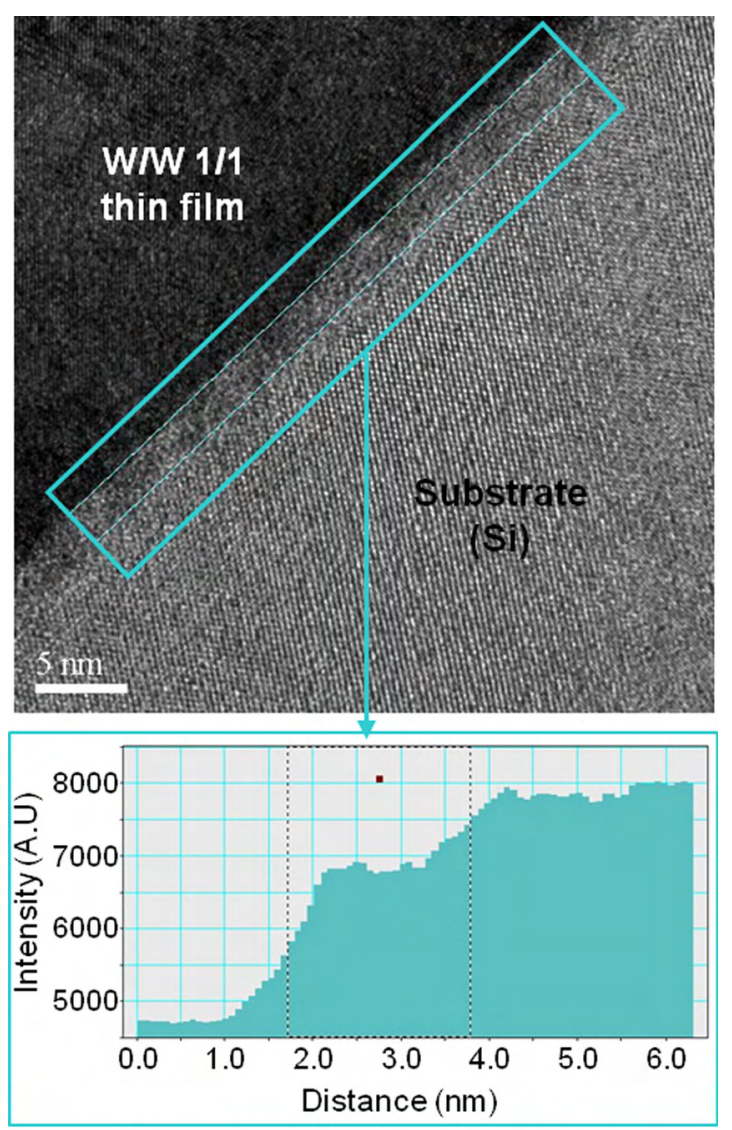

Film-substrate intensity profile

FIG. 8. BF-TEM image of interface between W/W 1/1 thin film and substrate with associated film-substrate intensity profile. 
(a) W/W 1/1

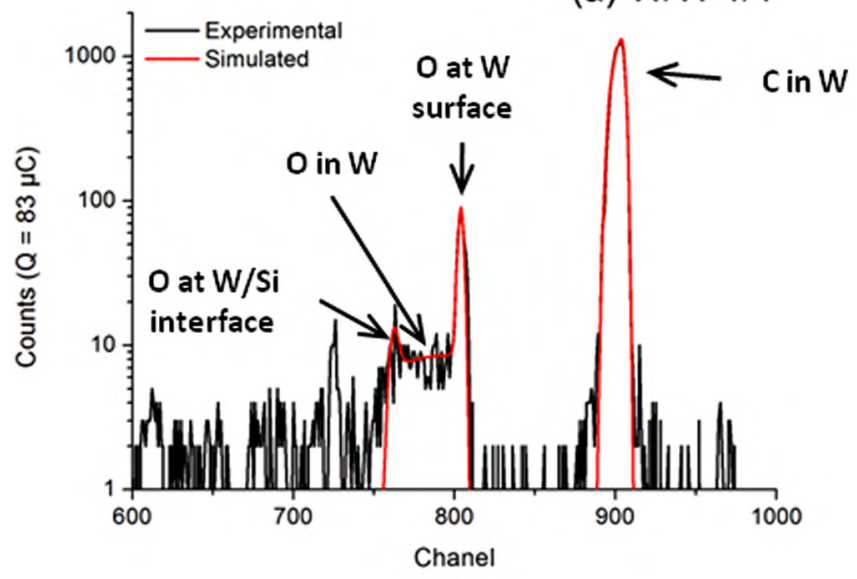

(b) W/W $8 / 8$

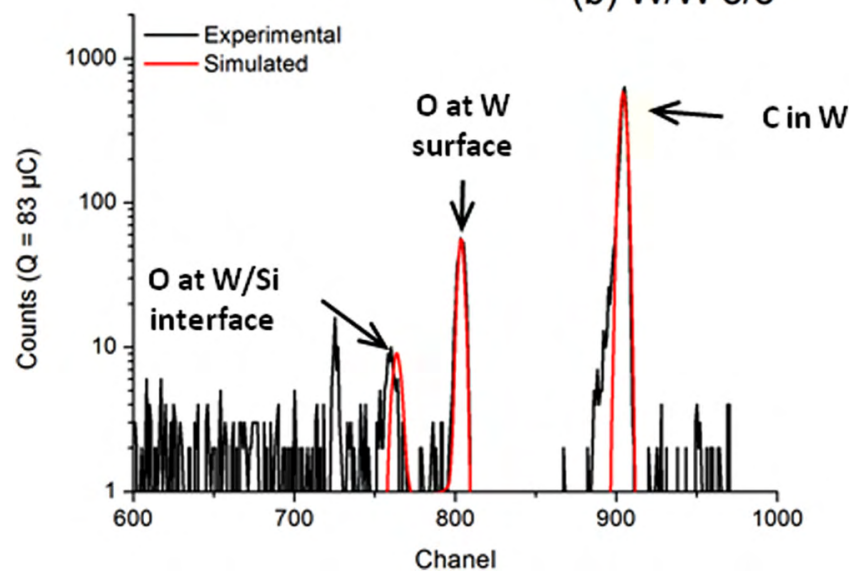

FIG. 9. NRA spectra carried out on (a) W/W 1/1 and (b) W/W 8/8.

Similar NRA analysis has also been performed on a sequenced tungsten deposition presenting a low $\beta$-W phase volume proportion, i.e., W/W 8/8 (Fig. 9(b)). NRA analysis shows even lower oxygen atomic proportion in volume $(0.2$ \pm 0.2 at. \%) but analogous oxygen atomic proportion at film-substrate interface and at film surface. Carbon content in volume is significantly lower in W/W 8/8: $3 \pm 1$ at. $\%$. It is noteworthy that NRA profile does not reveal the stratification observed on W/W 8/8, which may be explained considering the low in-depth resolution of NRA technique $(40 \mathrm{~nm}$ for $\mathrm{C}$, and $20 \mathrm{~nm}$ for $\mathrm{O}$, considering bulk tungsten density).

Although NRA technique confirms a larger oxygen atomic proportion in volume in W/W $1 / 1$ compared to W/W $8 / 8$ (7 times greater), the critical composition over which $\beta$ $\mathrm{W}$ phase is stabilized is not reached (reported to be between 5 and 15 at. $\%^{5}$ ). However, carbon contents observed have to be correlated to $\beta$-phase presence since it has been established that carbon atoms can also stabilize $\beta$-W in the same way than oxygen atoms. ${ }^{42}$

\section{DISCUSSION}

$\alpha$-W sample shows an original fiber texture with a mixture of $\langle 110\rangle$ and $\langle 111\rangle$ preferential crystallographic orientations. Texture evolution for polycrystalline thin films is generally driven by the minimization of the total free energy within a thermodynamic approach. ${ }^{43,44}$ A texture map showing the expected texture favored by grain growth as a function of the elastically accommodated strain and the film thickness can be determined. Noteworthy, the thicknesses involved in the present set of specimens are quite small compared to the thickness growth evolution reported in the literature. Moreover, as $\alpha-\mathrm{W}$ phase is perfectly elastically isotropic, the elastic strain energy stored during growth cannot be a driven parameter for texture evolution. In the present films, the development of $\alpha-\mathrm{W}\langle 110\rangle$ texture component during thin film growth by PVD of bcc materials can be explained by surface-energy minimization during deposition ${ }^{45-47}$ contrary to the case of $\alpha-\mathrm{W}\langle 111\rangle$ texture. Such an unexpected texture development has already been reported in tungsten films ${ }^{48,49}$ and has been observed in previous work on nanocomposite $\mathrm{W}-\mathrm{Cu}$ thin films under similar deposition conditions. ${ }^{50}$ Simultaneous presence of $\alpha-\mathrm{W}\langle 110\rangle$ and $\alpha-\mathrm{W}\langle 111\rangle$ texture components could originate from the competition between ion channeling effect and surfaceenergy minimization ${ }^{48,49,51}$ while surface stress or strain, ${ }^{52}$ and/or surface energy modification due to mixing effect ${ }^{53}$ might also be involved and could be enhanced at nanometric scales. ${ }^{54}$ This explanation is consistent with the stress-state difference observed between $\alpha-\mathrm{W}\langle 110\rangle$ and $\alpha-\mathrm{W}\langle 111\rangle$ texture components. According to previous works, such a texture is neither significantly affected by substrate ${ }^{55}$ nor underlayer (interfaces) roughness, ${ }^{56,57}$ nor related to $\beta$-W phase development. Nevertheless, even if $\beta$-W is not involved in the crystallographic orientation competition in $\alpha-\mathrm{W}$ (this is confirmed by the observation of a constant volume fraction ratio between $\alpha-\mathrm{W}\langle 111\rangle$ and $\alpha-\mathrm{W}\langle 110\rangle$ texture components), its presence affects the global volume proportion of $\alpha-\mathrm{W}$ phase and thus explains the low texture signal observed on W/W $2 / 2 \alpha-\mathrm{W}\langle 110\rangle$ pole figure.

All samples show tungsten $\beta$-phase which volume proportion remains roughly constant and weak for tungsten sublayers' thickness beyond $3 \mathrm{~nm}$. Under present deposition conditions, $\beta$-W develops with decreasing tungsten sublayers' thickness below $3 \mathrm{~nm}$ when $\beta$-W fully crystallizes (i.e., $\mathrm{W} / \mathrm{W}$ $1 / 1)$. In the literature, two different assumptions have been proposed for the formation of the $\beta$-phase having A15 structure. The first claim is that the presence of oxygen is a sine qua non condition to form the $\beta$-phase with the assumption that A15 structure is either related to a tungsten sub-oxide such as $\mathrm{W}_{3} \mathrm{O}$ and $\mathrm{W}_{20} \mathrm{O}$ (Refs. 58 and 59) or a tungstentungstide $\left[\mathrm{W}_{3} * \mathrm{~W}\right]$ structure containing tungsten ions in different oxide states in the lattice. ${ }^{60}$ The second claim is that the $\beta$-phase does not require oxygen in the lattice. ${ }^{61,62}$ In the present experiment, all XRR diagrams, with the exception of W/W 1/1 sample, show a low-angle diffraction Bragg's peak indicating a periodic density modulation that matches the sputtering sequence and thus suggesting in all likelihood impurity trapping occurring during deposition break. Despite observed reflectometry modulations, no visible interfaces were detected between tungsten sublayers on cross-sectional TEM views. This is consistent with the low reflectometry signal and HRTEM image analyses: large grain size distribution and mean grain size of the order of the deposited sublayers' thicknesses (controlled by sputtering sequence). TEM 
analyses carried out on $\mathrm{W} / \mathrm{W} 16 / 16$ showed that $\beta$-W phase is mainly localized at film-substrate interface, i.e., at the beginning of film growth (a band of 10-15 nm width). This observation is consistent with the work carried out by Maillé et al. ${ }^{63}$ who report an A15 structure development during the very first growth stages related to oxygen target pollution. It is often reported that oxygen presence in interstitial sites of the cubic cell tends to stabilize tungsten A15 structure. ${ }^{4,5}$ It is found that an oxygen concentration in the range of $5-15$ at. $\%$ is a transitional atomic proportion, which favors $\beta$-W development. In the present case, special attention was paid to target cleaning and thus oxygen contamination should not be attributed to the target but rather to oxygen diffusion from the native silicon oxide layer.

TEM observations carried out on W/W 1/1 specimen confirm that this sample is exclusively constituted by $\beta-\mathrm{W}$ phase and reveal unexpected nanometric crystallites since no reflectometry modulation was observed. Temperature and pressure involved during deposition process presented here should induce a Volmer-Weber type growth. This growth mode implies islet coalescence leading to tensile-stress state during the early thin film growth stages and thus favors $d e$ facto $\beta$-W development. ${ }^{7}$ Hence, increasing the interfaces number, i.e., decreasing the sputtering period aids $\beta$-W development. Then, the large stress difference between the residual stress values obtained by XRD and curvature methods could be explained by a stress relaxation mechanism occurring at $\mathrm{GB}$, interfaces and also in $\beta$-W crystallites. Noticeably, this difference increases with decreasing sputtering period, i.e., with increasing $\beta$-W volume proportion and also grain boundaries and interfaces proportions.

Quantitative NRA measurements analysis carried out on W/W 1/1 shows carbon and oxygen atomic proportion in volume of 16 and 1.5 at. \%, respectively. NRA spectrum analysis regarding to $\mathrm{W} / \mathrm{W} 8 / 8$ indicates significantly lower atomic proportions in volume: 3 at. $\%$ for $\mathrm{C}$ and 0.2 at. $\%$ for $\mathrm{O}$. Oxygen atomic concentration remains thus too low to justify the $\beta$-W phase development. In contrast, carbon contents show consistency with $\beta$-phase volume proportion (also reported as a $\beta$-W stabilizing agent ${ }^{42}$ ). Despite the use of high purity Ar gas bottle (>99.9999\%) and a very low residual vacuum $\left(<3 \times 10^{-8}\right.$ mbars $)$ mainly composed of water vapor and hydrogen, carbon and oxygen set in samples can originate from $\mathrm{CO}$ and $\mathrm{CO}_{2}$ surface desorption and/or $\mathrm{CO}_{2}$ permeation through elastomeric seals. Since vacuum supply during deposition process is exclusively carried out by the two cryogenic pumps, no primary pumping oil contamination should arise. In addition, cryogenic pumping allows better $\mathrm{CO}_{2}$ drain than $\mathrm{CO}$. Moreover, considering the uncertainties, carbon and oxygen content evolution between low (W/W 8/8) and high (W/ $\mathrm{W} 1 / 1) \beta$-phase volume proportion samples is consistent with the W/W interface number (199 for W/W $1 / 1$ and 24 for W/W $8 / 8$ over the constant $200 \mathrm{~nm}$ thin film thickness), and could thus be related to residual vacuum $\mathrm{CO}_{\mathrm{x}}$ molecule adsorption at W/W interlayer. Latter observation is also consistent with the step-by-step deposition sequences (inter-sublayers' break duration of $60 \mathrm{~s}$ ) since the time needed to form a monolayer at $10^{-4}$ mbar is $34 \mathrm{~ms}^{64}$ Yet, observed $\mathrm{C}$ and $\mathrm{O}$ atomic contents in both $\mathrm{W} / \mathrm{W} 1 / 1$ and $\mathrm{W} / \mathrm{W} 8 / 8$ respect neither carbon dioxide nor carbon monoxide stoichiometry but rather $\mathrm{CO}_{0.1}$ compound. Considering adsorbed $\mathrm{CO}_{\mathrm{x}}$ gas source for $\mathrm{C}$ and $\mathrm{O}$ sample content, this assessment suggests a significant oxygen release. Actually, the deposition resumption and thus associated $\mathrm{W}$ atoms bombardment can lead to a conversion of low (physisorbed) to high (chemisorbed) binding energy adsorption. ${ }^{65}$ Chemisorption binding energy is of the same order of the incident atom energy (4-5 eV per molecule) while $\mathrm{CO}$ binding energies are, respectively, of $3.69 \times 10^{-3}$ and $8.24 \times 10^{-3} \mathrm{eV}$ for single and double bonds. Despite the low energy transfer in a collision event related to the large mass difference between incident $\mathrm{W}$ and $\mathrm{C}$ or $\mathrm{O}$ atoms, sample surface re-pulverization can thus lead to $\mathrm{CO}$ molecule cracks (C-O bond break) leading to oxygen release (easily evacuated by cryogenic pumps). Measured $\mathrm{C}$ and $\mathrm{O}$ contents would then be the result of a two-step process: $\mathrm{CO}$ chemisorptions, followed by $\mathrm{O}$ release on surface re-pulverization by $\mathrm{W}$ atoms.

Moreover, mixing effects resulting from ion implantation during thin film growth ${ }^{66}$ under energetic deposition process $^{67}$ (case of present IBS process) can also contribute to $\beta$-W development. A transition of thin film phase proportion is observed as the W sublayers' thickness is smaller than $3 \mathrm{~nm}$. Such an evolution can be explained considering grains nanostructuration. Indeed, the crystallite-size decrease controlled by sputtering sequence facilitates diffusion ${ }^{54}$ in particular for grain size smaller than $3 \mathrm{~nm}$. Thus, it might be expected that decreasing the period and grain size the diffusion coefficient increases for both oxygen and carbon and this phenomenon favors $\beta$-W phase growth. This hypothesis is consistent with phase analysis showing no evolution of $\beta$-W $\{200\}$ diffraction peak above $3 \mathrm{~nm}$ thick tungsten sublayers' thickness and a $\beta-\mathrm{W}$ volume proportion increase with decreasing tungsten sublayers' thickness below $3 \mathrm{~nm}$. Moreover, TEM observation of $\beta$-W band that extends on approximately $10-15 \mathrm{~nm}$ from the interface in W/W $16 / 16$ is in good agreement with those conclusions.

Finally, a small quantity of tungsten may be deposited while the shutter is closed; in this case, a Volmer-Weber deposition mode could tend to maintain crystallites in a tensile-stress state favorable to tungsten A15 structure. In the present case, this contribution is negligible since only $\mathrm{W} / \mathrm{W}$ $1 / 1$ is fully $\beta-\mathrm{W}$ phase composed.

This analysis is consistent with the phase analysis carried out in previous work on copper dispersoid W-Cu thin film composites ${ }^{50}$ where progressive increase of copper quantities between $3 \mathrm{~nm}$ thick tungsten sublayers led to $\beta$-W diffraction peak disappearance, copper incorporation acting as a diffusion barrier to oxygen and/or carbon atoms. ${ }^{68}$

\section{v. CONCLUSION}

Complementary techniques were used in order to evidence the controlled nanostructuration of tungsten thin films thanks to an original sequenced deposition method. Reflectometry and TEM measurements showed tungsten nanocrystalline structure with crystallite-size ruled by the sputtering sequence. A sublayers' thickness threshold for phase structure change is evidenced under the presented IBS process conditions: $\alpha$-W phase with bcc structure is obtained 
above $3 \mathrm{~nm}$ while $\beta$-W phase with A15 cubic structure is predominant below this threshold. The presence of carbon atoms at interfaces plays an important role in this out of plane nanostructuration since the induced electronic density variation at interfaces is sufficient to be measured by XRR. Furthermore, it favors $\beta$-W formation below $3 \mathrm{~nm}$.

Another important feature concerns the co-existence of two major preferential crystallographic orientations for $\alpha-\mathrm{W}$ phase namely $\langle 110\rangle$ and $\langle 111\rangle$ fiber texture components whereas $\beta$-W phase exhibits an isotropic texture. Residualstress selective analysis for both orientations by XRD suggested that texture development is related to stress state built in thin film during deposition process. The presence of both $\alpha-\mathrm{W}\langle 110\rangle$ and $\alpha-\mathrm{W}\langle 111\rangle$ texture components would be then attributed to the minimization competition between crystalline planes energy and defects formation. Nevertheless, interfaces chemical effects might also contribute. An extra deposit between tungsten sublayers is suspected and could affect the film energy and hence its texture development. No correlation is observed between the evolution of $\alpha-\mathrm{W}$ texture components proportion and $\beta-\mathrm{W}$ phase development.

Finally, new insights related to $\beta$-W phase development were achieved. Indeed, this phase is systematically detected while its volume proportion greatly increases with decreasing tungsten sublayers below $3 \mathrm{~nm}$ to reach fully $\beta$ nanocrystallized $\mathrm{W}$ for $1 \mathrm{~nm}$ sputtering sequence. For largest sputtering period $(16 \mathrm{~nm})$, HRTEM analysis revealed that $\beta$-W is located next to film-substrate interface (first $15-20 \mathrm{~nm}$ ). NRA measurements revealed a correlation between $\beta$-W localization and high carbon atomic proportion, and to a less extent, oxygen atomic concentration, both elements known as stabilizing agents of A15 structure in tungsten. Despite high vacuum quality, carbon and oxygen are supposed to originate from adsorption of residual $\mathrm{CO}$ at W/W interfaces (additional source from film-substrate interface for O). This could imply carbon and/or oxygen introduction in $\alpha$-W lattice (supported by freelattice parameter dilatation), trapped during deposition process and/or diffused from substrate-film interface. Their diffusion through the thin film is then facilitated by both deposition sequence (interfaces number) and diffusion coefficient increase with decreasing grain size below $3 \mathrm{~nm}$ and deposition conditions that favor Volmer-Weber growth mode. Finally, $\beta$-W development is sustained by tensile stresses induced by this growing mode and the increase of interface number with decreasing tungsten sublayers' thickness: surface reconstruction or impurities incorporations $(\mathrm{O}$ and $\mathrm{C})$. The large surfaceto-volume ratio related to nanostructure and the associated constraints from the film substrate allow the synthesis of material endowed with novel properties, controlled by their microstructure from atomic to macroscopic scale. ${ }^{31,69}$ Further investigations will be carried out in order to confirm this interpretation in particular considering in situ mass spectroscopy during deposition process.

${ }^{1}$ E. Lassner and W.-D. Schubert, Tungsten: Properties, Chemistry, Technology of the Element, Alloys, and Chemical Compounds (Springer, 1999).

${ }^{2}$ H. Zheng, J. Z. Ou, M. S. Strano, R. B. Kaner, A. Mitchell, and K. Kalantar-zadeh, Adv. Func. Mater. 21, 2175 (2011).
${ }^{3}$ D. Dellasega, G. Merlo, C. Conti, C. E. Bottani, and M. Passoni, J. Appl. Phys. 112, 084328 (2012).

${ }^{4}$ I. A. Weerasekera, S. I. Shah, D. V. Baxter, and K. M. Unruh, Appl. Phys. Lett. 64, 3231 (1994).

${ }^{5}$ Y. G. Shen and Y. W. Mai, J. Mater. Sci. 36, 93 (2001).

${ }^{6}$ M. J. O'Keefe and J. T. Grant, J. Appl. Phys. 79(12), 9134 (1996).

${ }^{7}$ Y. G. Shen, Y. W. Mai, Q. C. Zhang, D. R. McKenzie, W. D. McFall, and W. E. McBride, J. Appl. Phys. 87, 177 (2000).

${ }^{8}$ E. Le Bourhis, P. Goudeau, J.-P. Eymery, and W. Al-Khoury, Eur. Phys. J.: Appl. Phys. 30, 33 (2005).

${ }^{9}$ S. I. Shah, B. A. Doele, C. R. Fincher, K. M. Unrush, and I. Weerasekera, J. Vac. Sci. Technol. A 11, 1470 (1993).

${ }^{10}$ M. S. Aouadi, R. R. Parsons, P. C. Wong, and K. A. R. Mitchell, J. Vac. Sci. Technol. A 10, 273 (1992).

${ }^{11}$ M. Gasgnier, L. Nevot, P. Ballif, and J. Bardolle, Phys. Status Solidi A 79, 531 (1983).

${ }^{12}$ G. Hägg and N. Schönberg, Acta Crystallogr. 7, 351 (1954).

${ }^{13}$ T. Karabacak, P.-I. Wang, G.-C. Wang, and T.-M. Lu, Thin Solid Films 493(1-2), 293 (2005).

${ }^{14}$ G. M. Demyashev, A. L. Taube, and E. Siores, Nano Lett. 1(4), 183 (2001).

${ }^{15}$ N. C. Angastiniotis and B. H. Kear, Mater. Sci. Forum 179-181, 357 (1995).

${ }^{16}$ N. C. Angastiniotis, B. H. Kear, L. E. McCandlish, K. V. Ramanujachary, and M. Greenblatt, Adv. Powder Metall. 7, 29 (1992).

${ }^{17}$ A. Bosseboeuf, M. Dupeus, M. Boutry, T. Bourouina, D. Bouchier, and D. Debarre, Microsc. Microanal. Microstruct. 8, 261 (1997).

${ }^{18}$ H. S. Witham, P. Chindandom, I. An, R. W. Collins, R. Messier, and K. Vedam, J. Vac. Sci. Technol. A 11, 1881 (1993).

${ }^{19}$ M. Arita and I. Nishida, Jpn. J. Appl. Phys., Part 1 32, 1759 (1993).

${ }^{20}$ T. Kizuka, T. Sakamoto, and N. Tanaka, J. Cryst. Growth 131, 439 (1993).

${ }^{21}$ D. P. Basile, C. L. Bauer, S. Mahajan, A. G. Milnes, T. N. Jackson, and J. DeGelormo, Mater. Sci. Eng., B 10, 171 (1991).

${ }^{22}$ A. M. Haghiri-Gosnet, F. R. Ladan, C. Mayeux, and H. Launois, Appl. Surf. Sci. 38, 295 (1989).

${ }^{23}$ E. K. Broadbent, J. Vac. Sci. Technol. B 5, 1661 (1987).

${ }^{24}$ Y. Pauleau, P. Lami, A. Tissier, R. Pantel, and J. C. Oberlin, Thin Solid Films 143, 259 (1986).

${ }^{25}$ A. J. Learn and D. W. Foster, J. Appl. Phys. 58, 2001 (1985).

${ }^{26}$ J. H. Souk, J. F. O'Hanlon, and J. Angillelo, J. Vac. Sci. Technol. A 3, 2289 (1985).

${ }^{27}$ A. Bensaoula, J. C. Wolfe, A. Ignatiev, F. O. Fond, and T. S. Leung, J. Vac. Sci. Technol. A 2, 389 (1984).

${ }^{28}$ W. D. Nix, Metall. Mater. Trans. A 20, 2217 (1989).

${ }^{29}$ R. P. Vinci and J. J. Vlassak, Annu. Rev. Mater. Sci. 26, 431 (1996).

${ }^{30}$ J. Schiøtz, T. Vegge, F. D. Di Tolla, and K. W. Jacobsen, Phys. Rev. B 60, 11971 (1999).

${ }^{31}$ S. Yip, Nature 391, 532 (1998).

${ }^{32}$ H. Van Swygenhoven and J. R. Weertman, Mater. Today 9, 24 (2006).

${ }^{33}$ S. Cuenot, C. Frétigny, S. Demoustier-Champagne, and B. Nysten, Phys. Rev. B 69, 165410 (2004).

${ }^{34}$ F. Spaepen and D. Y. W. Yu, Scr. Mater. 50, 729 (2004).

${ }^{35}$ E. Arzt, Acta Mater. 46, 5611 (1998).

${ }^{36}$ M. A. Meyers, A. Mishra, and D. J. Benson, Prog. Mater. Sci. 51, 427 (2006).

${ }^{37}$ I. C. Noyan and J. B. Cohen, Residual Stress Measurement by Diffraction and Interpretation (Springer, New York, 1987).

${ }^{38}$ V. Hauk, Structural and Residual Stress Analysis by Non Destructive Methods: Evaluation, Application, Assessment (Elsevier, Amsterdam, 1997).

${ }^{39}$ P. Villain, P. Goudeau, J. Ligot, S. Benayoun, K. F. Badawi, and J.-J. Hantzpergue, J. Vac. Sci. Technol. 21(4), 967 (2003).

${ }^{40}$ N. Durand, K. F. Badawi, and P. Goudeau, J. Appl. Phys. 80, 5021 (1996).

${ }^{41}$ A. H. Al-Bayati, K. Ormannn-Rossiter, J. A. van den Berg, and D. G. Armour, Surf. Sci. 241, 91 (1991).

${ }^{42}$ P. K. Srivastava, V. D. Vankar, and K. L. Chopra, Thin Solid Films 161, 107 (1988).

${ }^{43}$ C. V. Thompson, Annu. Rev. Mater. Sci. 30, 159 (2000).

${ }^{44}$ V. Consonni, G. Rey, H. Roussel, and D. Bellet, J. Appl. Phys. 111, 033523 (2012).

${ }^{45}$ S. G. Wang, E. K. Tian, and C. W. Lung, J. Phys. Chem. Solids 61, 1295 (2000).

${ }^{46}$ Y. Gotoh, S. Entani, and H. Kawanowa, Surf. Sci. 507-510, 401 (2002).

${ }^{47}$ J. M. Zhang, D. D. Wang, and K. W. Xu, Appl. Surf. Sci. 252, 8217 (2006). 
${ }^{48}$ T. Ganne, J. Crépin, S. Serror, and A. Zaoui, Acta Mater. 50, 4149 (2002).

${ }^{49}$ G. Carter, Phys. Rev. B 62, 8376 (2000).

${ }^{50}$ B. Girault, D. Eyidi, T. Chauveau, D. Babonneau, P.-O. Renault, E. Le Bourhis, and P. Goudeau, J. Appl. Phys. 109, 014305 (2011).

${ }^{51}$ D. Dobrev, Thin Solid Films 92, 41 (1982).

${ }^{52}$ L. H. He, C. W. Lim, and B. S. Wu, Int. J. Solids Struct. 41, 847 (2004).

${ }^{53}$ E. Ma, Prog. Mater. Sci. 50, 413 (2005).

${ }^{54}$ G. Guisbiers and L. Buchaillot, Nanotechnology 19, 435701 (2008).

${ }^{55}$ R. Hoogeveen, M. Moske, H. Geisler, and K. Samwer, Thin Solid Films 275, 203 (1996).

${ }^{56}$ C. E. Murray, K. P. Rodbell, and P. M. Vereecken, Thin Solid Films 503, 207 (2006).

${ }^{57}$ N. R. Shamsutdinov, A. J. Böttger, and F. D. Tichelaar, Scr. Mater. 54, 1727 (2006).

${ }^{58}$ M. G. Charlton, Nature 174, 703 (1954).

${ }^{59}$ W. D. Schubert, Int. J. Refract. Met. Hard. Mater. 8, 178 (1990).
${ }^{60}$ S. Geller, Acta Crystallogr. 10, 380 (1957).

${ }^{61}$ A. B. Kiss, J. Therm. Anal. 54, 815 (1998).

${ }^{62}$ C. L. Chen, T. Nagase, and H. Mori, J. Mater. Sci. 44, 1965 (2009).

${ }^{63}$ L. Maillé, C. Sant, C. Le Paven-Thivet, C. Legrand-Buscema, and P. Garnier, Thin Solid Films 428, 237 (2003).

${ }^{64} \mathrm{G}$. Rommel, Gaz à très basse pression Formules et tables, Editions Techniques de l'Ingénieur, 1985.

${ }^{65}$ G. K. Hubler and J. A. Sprague, Surf. Coat. Technol. 81, 29-35 (1996).

${ }^{66}$ W. Hiller, M. Buchgeister, P. Eitner, K. Kopitzki, V. Lillienthal, and E. Peiner, Mater. Sci. Eng., A 115, 151 (1989).

${ }^{67}$ J. A. Thornton and J. E. Greene, in Handbook of Deposition Technologies for Films and Coatings, 2nd ed., edited by R. F. Bunshah (Noyes, Park Ridge, NJ, 1994).

${ }^{68}$ V. D. Osovskii, Y. G. Ptushinskii, V. G. Sukretnyi, B. A. Chuikov, V. K. Medvedev, and Y. Suchorski, Surf. Sci. 377-379, 664 (1997).

${ }^{69}$ H. Huang and F. Spaepen, Acta Mater. 48, 3261 (2000). 